\title{
Agricultural Policy Issues in Pakistan
}

\author{
MAHMOOD HASAN KHAN*
}

\section{INTRODUCTION}

Agriculture, in many ways, remains the most dominant activity in Pakistan. It provides a way of life to almost three-quarters of the country's population: over 55 percent of the labour force works directly in agriculture and about 30 percent of the Gross Domestic Product and over 35 percent of the export earnings were contributed by agriculture in 1983. That three-quarters of the population engaged in agriculture cannot produce adequate supply of food and fibre at reasonable prices for the one quarter working in other sectors indicates a low level of productivity in crop and livestock production. Agricultural growth in the past 35 years or so has been uneven in terms of both rates and commodity balances. Also, the benefits from growth have varied significantly across regions and between farm groups. Markets and public policy have not always provided the right economic incentives and environment for sustained and equitable growth.

There is considerable potential for increasing agricultural production in Pakistan, notably through an efficient use of available resources and technology. In the short to medium term, increased inputs, especially fertilizer, combined with better timing of water and simple improvement in farm practices such as weeding and increased plant densities, can substantially increase crop output. In the long run, however, major efforts to strengthen the institutional framework for incentives will have to be part of a strategy to transform the agricultural sector. Sustained and equitable structural change in agriculture would require significant readjustments in the land tenure and land revenue, as well as improvements in agricultural research, extension, water management, and the marketing system. 


\section{A POLICY PERSPECTIVE}

As shown by the aggregate growth rates tabulated below, the performance of agriculture has not been spectacular or stable in the last 35 years.

\section{Period}

1950-1955

$1955-1960$

1960-1965

1965-1970

1970-1975

1975-1980

1981-1982

1982-1983

Annual Growth Rate (Percent)

16

1.8

3.4

4.1

1.9

3.0

3.3

4.8

These growth rates show that the Fifties were a period of near-stagnation, followed by the robust growth period of the Sixties with visible slow-down in the early Seventies and some recovery in the late Seventies. The first two years of the Eighties have each shown a healthy growth rate of about 4 percent.

The highly aggregate growth rates in the agricultural sector do not, of course, reveal several important aspects of growth and distribution. Firstly, not all subsectors of agriculture have experienced sustained growth, which is amply demonstrated by serious commodity imbalances within one crop year and over time. Secondly, not all growth in output, even in those activities in which it has been experienced in any significant way, has come about because of increased efficiency or at lower cost. Thirdly, growth experience, even in the Sixties, was highly uneven between various regions even within one province, particularly between regions with and without irrigation. Of course, provinces with limited irrigation facilities and infrastructure have been similarly handicapped. Finally, farm groups have also been affected unequally, depending upon their access to land and other related incomeearning opportunities within agriculture. All these generalizations cannot be demonstrated with precision mainly because of data problems, but they are supported by a substantial body of evidence from the primary (farm-level) and secondary (aggregate) data.

While the need for urgent national efforts to improve living standards has been endorsed by successive governments, public policy on agriculture has undergone several significant changes. The balance between private and public domains in agriculture has shifted according to the political predilections of the ruling party or group. These changes have, in turn, affected production, employment and income distribution. An overview of these changes would be useful for understanding the policy issues of today.
The Fifties can best be described as a period of benign neglect. Agricultural surpluses of food and fibre of the late Forties and early Fifties disappeared by the mid-Fifties. Public policy did little to create incentives for increased efficiency in agriculture.

Following the Martial Law in 1958, several policy changes were introduced. Adjustments were made in the land tenure system, and tenancy reforms were introduced. However, the major thrust of the "pragmatic" strategy of development was on input subsidies and support prices. Significant surface- and ground-water development, increasing use of fertilizer and use of the high-yielding varieties in the late Sixties also made an impressive impact on the yield levels of most of the major crops. It should also be noted that little or no consideration was given in this policy to issues of uneven distribution of growth by regions and unequal distribution of income among farm groups.

This period was followed by about six years of an "interventionist" public policy, which emphasized the central role of the State in the production and distribution systems. Changes were introduced in the land tenure system, followed by public control of the bulk of marketing and even processing of major agricultural commodities and distribution of inputs. Agricultural production was depressed in the early to mid-Seventies for several reasons, of which uncertain climate for new investment and unfavourable weather were probably the most significant.

After the imposition of Martial Law in mid-1977, the new government initiated a policy which has reduced direct State control of several activities. More recently, the government has adopted an agricultural strategy which relies less on subsidies and more on support prices for agricultural commodities. Also, it is designed to divert funds from subsidies to quick-yielding investments and support services to improve the effective use of resources in the agricultural sector. It is in some ways a policy similar to the pragmatic strategy followed in the Sixties with some sensitivity to small farmers, employment and income distribution.

\section{AGRICULTURAL POLICY ISSUES}

There are many and complex issues in agriculture. For analytical convenience, they can be devided into:
(i) Agricultural Inputs;
(ii) Agricultural Services; and
(iii) Institutions and Policy Instruments.

\section{Agricultural Inputs}

Production and distribution of several agricultural inputs are of critical importance to expansion of agricultural production. It is equally important to consider their quality, delivery and cost. We will here consider only fertilizers, tractors and 
water. Inputs like quality seed and pesticides are, of course, also important for rapid agricultural growth.

\section{Fertilizers}

Generally, chemical fertilizers in Pakistan are used on a limited number of crops and mainly in the irrigated areas. To encourage the use of fertilizers in adequate quantity and with proper nutrient combination, price subsidy has been used. This subsidy has been absorbed by the difference between the fixed price paid by farmers and the cost of domestic and imported fertilizer.

Rapid increases in the cost of production at home and in foreign markets in the late 1970 s increased the burden of fertilizer subsidy quite significantly. The present government has implemented two important policy changes. First, it has handed over the distribution of fertilizers to the private sector, to be sold by either dealers or cooperatives. Second, it increased sharply the sale prices of most fertilizers in February 1980. There is little evidence that the price increase has in fact adversely affected the crop output. It is possible that the higher cost of fertilizer induced greater care and efficiency and, with favourable weather, offset the reduction in the quantities applied. The short-term supply situation looks satisfactory, although this may be entirely due to the reduced use of fertilizer itself. For the long term, Pakistan has the raw material, including energy, to increase domestic production substantially for nitrogenous and phosphatic fertilizers at internationally competitive prices for both domestic use and possible exports.

A proper balancing of nutrients in the soil not only requires the use of chemical fertilizer but also of farmyard manure and green manuring. While chemical fertilizers have received much attention, there has been no systematic policy to encourage the use of manure and the practice of green manuring at the farm level.

\section{Mechanization}

The impact of mechanical inputs on growth and agrarian structure has been a subject of considerable controversy in Pakistan. This applies particularly to the use of tractors whose number has increased rapidly since the mid-Sixties. In general, the case for tractors is premised on the argument that they make agriculture efficient by their positive effects on (a) cropping intensity, (b) yield level, and (c) land preparation and post-harvest operations.

On the other hand, there are doubts about some of these positive effects, particularly on the yield level and multiple cropping. More importantly, it has been contended that tractorization in Pakistan has resulted in (a) labour displacement and tenant eviction, and (b) expansion of holdings which are already large. Implied in these arguments is the notion that rich peasants and landlords are increasingly encroaching on lands which were available for cultivation to poor peasants and share-croppers. While there is no conclusive evidence on net displacement of labour due to tractors, the position of share-croppers on the landlord estates has weakened as less of their time and power of their animals are required for land preparation and post-harvest operations. The traditional strength of the share-cropper, represented by his family labour and animal power, has been undermined as the landlord is now even less willing to share the benefits of new technology associated with fertilizer-waterseeds-tractors.

The process of tractorization, dominated by large tractors (over $35 \mathrm{HP}$ ), owed its inception to pressure from large landowners. It has in turn led to concentration of tractor ownership on the one hand and pressure for expansion of area under large holdings, both of landlords and of rich peasants, on the other. The tractor market, dependent on imports, has been closely regulated by the federal government. Public policy has so far consistently favoured the import and use of large tractors. In fact, a ban on the import of tractors of less than 33 HP was lifted only in mid-1982. The government has also provided handsome incentives for the purchase of tractors through (a) reduced import duties and taxes, and (b) A.D.B.P. loans at low rates of interest. The tax-credit subsidies have remained high even with rapidly increasing demand for tractors by large landowners. The price structure of imported tractors in Pakistan compares favourably with what American farmers pay in the domestic market.

\section{Irrigation Water}

Water is one of the most important inputs constraining Pakistan's agriculture. The barani (rain-fed) areas provide good evidence that an inadequate and unstable supply of water can impede the development of efficient agriculture. In the irrigated areas, surface-water development has been both impressive and costly. Poor designing and drainage of irrigation canals in the Indus basin have created the menace of waterlogging and salinity, which are also aggravated by poor soil conditions and improper water management at the farm level.

There are at least three policy aspects of the surface water system. Firstly, there is the problem of maintaining and rehabilitating the canals because of inadequate funding and neglect by the provincial Irrigation Departments. Related to this is the problem of inadequate and unstable supply of water to users, which is mainly because of a lack of co-ordination between the provincial Irrigation and Agriculture Departments. The federal government has recently asked the provincial governments to establish interdepartmental committees to minimize this problem. The second serious problem is of water losses in the meandering watercourses that link canals to the farmers' fields. Considering these losses, a joint Pakistan-USAID On-Farm Water Management (OFWM) pilot project was launched in 1977 on selected watercourses in the Punjab, Sind and the NWFP. It included cleaning, straightening 
and partial lining of watercourses, and installation of pukka nukkas (concrete distribution inlets). The provincial governments have established technical departments to facilitate this work, and they have recently enacted Water Users Association Ordinances. It is hoped that these Associations will facilitate improvement and maintenance of watercourses within a co-operative framework.

It has been shown, at least in the OFWM pilot project, that a considerable saving of water and labour can be achieved at reasonable cost if the water users maintain the improved watercourses. In fact, the provincial governments, with help from the World Bank, have now a nationwide project under way to cover most of the watercourses in the next five to ten years.

Finally, the problem of waterlogging and salinity, serious as it has been in some areas, is still increasing. The reclamation efforts have been costly and not entirely satisfactory. Following the recommendation of the RAP document, prepared by the WAPDA with help from the UNDP/World Bank, the government has announced its intent to restructure the Salinity Control and Reclamation Projects (SCARPs), although the new structure has not been indicated so far.

One important policy change, as least in the sweet-water areas, is that the public-sector tubewells will be sold to the private sector. For such a sale, a credit scheme has been prepared. Public sector will now be involved only in siting wells and laying electric networks. Subsidy on diesel tubewells will continue in areas where electricity cannot be provided easily or cheaply.

\section{Agricultural Services}

There are several public-sector services which are needed to improve the production and distribution of agricultural inputs and commodities. Among these, credit, marketing, education, research and extension are analysed here.

\section{Credit}

Credit is the bridge leading from subsistence to cash economy and, eventually, to investible surplus. Despite the substantial growth of institutionalized credit in recent years, much of it is still beyond the reach of many cultivators. Share-croppers are, of course, almost entirely excluded, as landlords have the only asset that counts as collateral for loans. Small owners have to go to relatives and money-lenders. Competition for credit from government sources favours large landowners, whose needs are not as pressing as those of small farmers.

Nationalized commercial banks, Agricultural Development Bank of Pakistan (ADBP), and Co-operative Banks are now the three major sources of institutionalized credit. The Co-operative Banks have, in fact, been involved in a programme of interest-free loans of up to Rs. 6,000 to owners of 12.5 acres or less. The smallfarmer credit scheme has, however, created the problem of false land registration and petty corruption. While the supervised and in-kind credit appears cost-effective and efficient in inducing the use of fertilizer by the small farmer, there are doubts if rapid expansion of credit can be mobilized and delivered to the target group.

Also, recovery of the expanded credit may not be easy as the more recent experience has been on a much smaller volume of credit. Lending through co-operatives, guaranteed by the provincial governments, may also lead to the fiscal burden of the government. Commercial banks and the ADBP are still mainly catering for the long-term credit needs of large farmers, particularly in financing their purchases of tractors etc. The basic policy issue, therefore, still relates to the timely delivery of credit in amounts most needed by small farmers to make them productive, thus increasing their capacity to repay the loans.

\section{Storage and Marketing}

The need for adequate storage of certain agricultural products has been felt for a long time. Proper storage at the farm and national levels can stabilize prices and the supply of major food and cash crops for domestic consumption and exports. Recently, there has been an increased emphasis on expanding the national storage facilities, both within the public sector and through co-operatives. However, it has also been argued that, at least for wheat, a private storage-programme should be encouraged by the support price mechanism. It has been suggested that the procurement price of wheat should be increased gradually in the post-harvest season. This will induce the wheat farmers to improve their own storage facility and also to save the public sector the enormous costs involved in building these facilities.

Private markets for agricultural goods are quite fragmented and many are still unregulated. In the domestic markets the government participates in varying degrees, and export trade of some agricultural commodities is entirely in the hands of the public sector. In the last $3-4$ years, there has been a definite shift towards a freemarket system. In this, the government has emphasized the need for co-operatives and public corporations to compete with the private trading-agents. While the government has expressed a desire to facilitate the private sector in export trade with planning and guidance provided by the public sector, no definite programme has been announced. However, the private sector has been assigned almost total control of marketing inputs like fertilizers and pesticides. Similarly, the processing of major crops has been returned to the private sector, from which it was taken away in the
mid-Seventies.

The federal government has increased its involvement in transporting certain agricultural goods and inputs through the National Logistics Cell to facilitate the movement of goods to markets which the private sector alone cannot at present provide. 


\section{Education, Research and Extension}

Improved organization of existing knowledge about improved farming methods is urgently needed to increase the farmers' capacity for higher levels of production and incomes. This will depend largely on educational facilities and adaptive research for better diagnostic and technical support system for farmers. These aspects of agricultural education, research and extension have been very weak in Pakistan. Agricultural education has expanded quite rapidly, but the standard of education has probably fallen considerably. Educational institutions at present are not suitably integrated with research and extension services.

Agricultural research in Pakistan has faced several problems. For one thing, the institutional system of research is complex and fragmented between the federal and provincial governments. There has been no national review-procedure to evaluate the research work, and there is considerable duplication of effort. Many gaps in technology remain even in the area of major crops on which most of the research has focused. Little emphasis has been placed on adaptive research for major crops, livestock and farm management. Inadequate funding, weak institutional framework and lack of appropriate work-environment and incentives for researchers have also contributed to a poor research-performance in the country.

The federal government has, by and large, accepted the recommendations of the World Bank on reorganizing the Pakistan Agricultural Research Council (PARC) and establishing a co-ordinated research network around the country. This will also include adaptive research in fields in which little and fragmented knowledge exists. It also emphasizes the need to collect and process agricultural economics data, which are at present grossly inadequate in quantity and quality. The problem of co-ordination between various research facilities within each province and between provinces is still a serious issue.

A little but correct knowledge can be a wonderful thing. To improve the management of land and water, an effective extension service, integrated with a vigorous educational and research system, is essential. The extension service is unable to provide technical service and assistance to.farmers on a regular basis for several reasons. Important among these is the small number of agents, who are too thinly distributed and who have inadequate mobility, training and motivation.

The Training and Visit ( $\mathrm{T} \& \mathrm{~V}$ ) system of extension has now been accepted as an effective method of providing the necessary help to farmers about improved practices. With the help of the World Bank, and as a part of crop-maximization programmes, the $T \& V$ has been launched in Sind and the Punjab on a limited basis. The project hopes to cover about 20-25 percent of the farmers by 1983-84. One of the major constraints in expanding an effective extension service in Pakistan is still the lack of funds to recruit, train and supervise extension agents. No less important perhaps is the problem of delivering it equally effectively to small and large farmers, as the information agent follows the size of holding or economic (and political) influence of the prospective demander of his service.

\section{Policy Instruments}

Sustained and equitable growth in the agricultural sector would require use of several policy instruments. It seems appropriate to consider at least three of them here.

\section{Land Reforms}

The structure of private arrangement on and about land, including production and marketing activities, and public institutions, including the fiscal instruments of the State, determine the direction and growth of agriculture.

Most regions in Pakistan have a highly differentiated structure of land tenure, in which the small cultivator asymmetrically co-exists with the large landowner, the share-cropper co-exists with his landlord, and so on. Participation in the market-place, as in the public-sector activities, is closely associated with one's position in this hierarchy of interests on land. It is therefore necessary to examine the problem of incentives, including price support and subsidies, by first recognizing the mass of producers who at present do not participate in the market, as their marketable surplus is small or is acquired by others as rent.

The land reforms of 1959 and 1972 have not radically altered the high concentration of landownership in most areas, although they have given to the tenants increased security of tenure on land. The small plots cultivated by share-croppers, as in many areas of Sind and in some areas of the Punjab, suffer from the imposition of high ground-rent by landlords, who are, by and large, absentee landowners. The small landowners are also under the pressure of large landowners, who have enjoyed a visibly high place in the development programmes of the government and exert most influence on markets and public-sector activities. Small and marginal landowners also face a serious problem of land fragmentation, and the consolidation schemes have not been quite satisfactory. The increasing fragmentation due to rapid population growth and the Muslim laws of inheritance not only poses a serious threat to the owners but also represents a considerable economic waste for the society.

Without a radical readjustment in the land-tenure system, the target groups of small farmers (owner-cultivators and the landless) will have to rely on the institutional support available within the present social system. It is important here to point out that since there is evidence in Pakistan that small farmers have higher yieldlevels and intensities of land and labour than large farmers, a policy that supports or encourages the growth of large farms would not necessarily be prudent. Its adverse consequences for employment and income distribution are likely to polarize the society beyond repair. 


\section{Agricultural Taxation}

Indirect taxes on agriculture have been the major means of transferring a part of the agricultural surplus to the State. One of the most controversial forms of indirect taxation was the export duties on cotton and rice, which the government has recently abolished. With increased support prices for major agricultural commodities, it has reduced the implied indirect tax as well.

The only direct tax on agriculture is the land tax (called land revenue), which is charge on the basis of on outdated valuation of net assets (or net income) of the landowners. The rate does not vary with the size of landholding, and it has no relationship with agricultural income. The tax structure is, therefore, rigid and unresponsive to changes in agricultural production and income. As it yields fixed amounts of revenue each year, it has fallen considerably as a proportion of the value of agricultural production and of other revenues.

The previous government introduced in the mid-Seventies some changes in the land-tax system by raising the rates paid by the landowners of 12.5 acres or more and exempting from payment the owners of smaller holdings. It then enacted a law in early 1977, abolishing the land revenue and replacing it with an income tax system similar to the one used for non-agricultural incomes. The present government, however, suspended the new agricultural income tax law and reverted to the land tax with ad hoc increases in the rate of payment until the Rabi season of 1982-83.

The introduction of ushr as tax on agricultural ouput from the Rabi season of 1982-83 has further clouded the issue of direct taxation in agriculture. Land revenue will still remain as a tax on the agricultural land of those who as non-Muslims (or even as Muslims) would not be liable to pay ushr. It is still early to say if ushr, even as a tax on income, would necessarily transfer a substantial portion of private incomes to the State. Ushr is clearly a fixed proportion of gross produce (less expenses), irrespective of the level of production or income. Also, it is not clear if any part of the ushr revenue would be available for developmental purposes in rural areas.

In the absence of a progressive direct tax on agriculture, investible surplus remains in the hands of those whose incomes have increased because of their preferred position in the market-place and in public-sector activities. Because of the limited and fixed amount of the revenue generated by land tax, the government has resorted to several types of explicit and implicit indirect taxes on agricutlure which have had few visible, if any, positive effects on efficiency and equity. A better use of land, and transfer, to the State, of a part of the private surplus which public subsidies help to create, since there has been a definite shift away from indirect taxes for revenue and equity should now get a proper place on the policy agenda.

\section{Support Prices and Subsidies}

State intervention in the pricing of agricultural products has been based on at least two arguments. First, it is argued that it can provide the necessary incentives to farmers to ise yield-increasing inputs. Secondly, it is argued that it can stabilize agricultural incomes and perhaps keep them in line with the changes in nonagricultural incomes. It is obviously important that current price signals are given to farmers to avoid less than optimal substitution between crops and to encourage maximum growth of crop output. Similarly, input prices should create incentives without imposing a serious financial burden on the economy.

In the last 2-3 years, the government has moved in the direction of substantial increases in support prices of major crops, and it has abolished export duties on most agricultural commodities. At the same time, subsidies on fertilizer, pesticides and water rates have been reduced substantially. Following the recommendations of the RAP document, an Agricultural Prices Commission has been established to recommend the extent and timing of appropriate adjustments in the pricing of agricultural inputs and ouputs.

One of the critical issues in the pricing of inputs has been the charge on canal water. There is evidence that expenditures on maintaining and rehabilitating the irrigation system are falling short of the needed resources. The government is now contemplating transfer of these expenditures from the recurring to the development components of provincial budgets. There is now clear recognition that water should be priced at much higher rates than the ones that are being paid in order to economize the use of water and to recover a substantial portion of the costs of maintaining and rehabilitating the canal system. Water rates have been increased recently, although the political realities have not allowed the government to increase them by as much as may have been warranted. 


\section{Comments on}

\section{"Agricultural Policy Issues in Pakistan"}

In his presentation, Dr. Khan has moved away considerably from the views that he presented in the paper which is being circulated. This leads me slightly unprepared. However, not much damage has been done. I shall restrict my comments to the original paper which has been circulated. From time to time I shall refer to some of the points raised by Dr. Khan in his oral presentation. I shall keep my discussion very brief. I found that Prof. Khan's presentation was not only moderate in tone compared to what he is writing elsewhere but unfortunately in scope as well. Although he touches a very wide range of issues in agricultural economics, he merely catalogues them. He did not get into enough detail particularly for the discussant to catch hold of a point and focus attention on that. There are issues ranging from fertilizer subsidy to $u s h r$, and that is a very broad range. There is very little that one can disagree with if you just catalogue facts within each of these broad headings. What I do take some exceptions to is that Prof. Khan has used some words which can mean different things to different people. There is a free-flowing use of terms, such as equity, fairness, bipolar policy, asymmetrical land relations, etc. These things have different meanings for different people. Unless one clarifies such terms, I am afraid, such concepts merely remain high-sounding words. After cataloguing the issues, Prof. Khan does not get into the meat of the problem for, as he explained, reasons of data problems. What I will try to do now is to present very briefly what in my view are some of the important issues and how I would have liked to have these issues addressed.

Broadly speaking, three major policy concerns in agriculture relate to (i) growth in agricultural output, (ii) employment generation and (iii) redistribution. The instruments to achieve growth in agricultural output are subsidies on fertilizers and seeds, extension services, etc. Since these constitute a package of inputs, these should be provided to the farmer at a subsidised rate. Where the employment issue is concerned, the specific policies of the government - for example, that concerning mechanization - need to be analysed for their impact on the employment prospects. Is mechanization good or bad? Does it lead to higher output or 
not? These issues are debatable. Evidence on such issues needs to be systematically gathered. It would be interesting to know whether it affects employment in agriculture in a way that it becomes an undesirable policy objective. Third is the question of redistribution. As for redistribution, drastic measures such as drastic land reforms or second best tools such as land revenue and subsidies may be employed as instrument of redistribution. So these then are the three important policy issues and some of the instruments used to achieve the policy objectives. Now obviously, the three are closely interlinked. One cannot expect to have a policy which yields increases in output without affecting employment in any way. Similarly, one cannot expect to have a policy which results in increased output without seriously affecting the pattern of land holding. Thus a sensible approach to any one of these issues would have to take into consideration the other two issues as well. I give you an example. At the heart of the debate on mechanization, the major point is that tractors lead to increased output. Those who favour mechanization argue that perhaps not so much in terms of increased yields as in terms of enhanced cropping intensity, tractors do contribute to raising agricultural productivity, and, therefore, a policy which subsidizes tractors or at least subsidizes credit for purchasing tractors is a good policy. As opposed to that view there is now a growing body of evidence which suggests that if you use tractors, you displace workers at least in the short run and also you change the pattern of holding so that the large farmers have greater incentive to cultivate most of the land themselves and in that way displace the tenants. So, you have got to weigh the output gain, if there is any, of mechanization through tractors against the cost of increasing unemployment and against the cost of increasing the size of farm in the agriculture sector; but then the problems are compounded further when we consider yet another aspect of mechanization. For example, we go with the most recent major change in agriculture, what agronomists call the thresher revolution which has completely changed the rural scene particularly at harvesting time. We know that threshers are good for agriculture. They do increase yields because they avoid crop losses at a crucial time but at the same time we are also aware that they do tend to displace labour but they tend to displace labour at a time when there is a peak of agricultural activities so that there are plenty of alternative employment opportunities for the displaced labour. That is not a very serious problem. However, threshers run with tractors. They are attached to tractors, so that you cannot discuss the mechanization policy which concerns tractors without at the same time affecting machinery which is seen to increase productivity without at the same time cosidering implications for the other items of agricultural machinery.

What I am really trying to say is that in a discussion of policy issues such things ought to be brought into forefront along with a summary of the existing literature and there is a growing body of literature in these areas. Secondly, there is a question of land reforms. Land reforms policy has also been discussed extensively in the
South Asian context in general, and also in Pakistani context, and it has been, for example, in a recent book Land to the Tiller by Ronald Herring who was associated with the PIDE for a year several years ago. He presents a very interesting but a well-known thesis that land is not the only factor which is controlled by landlords with respect to the relations between the landlord and the peasant; it is also access to government service, so that one should not talk about just land as the only factor which should be affected through a redistributive policy. All the other inputs which are affected because of land concentration would also have to be taken into account so that the policy of land reforms which ignores reform of credit institutions as well as the restructuring of extension services would be of little value. And, again, there is a growing body of literature which presents evidence on one side or the other. One would have expected a discussion of that body of literature and the summing up of the position so that the planners can have a specialist's view of the matter and would be guided in making their policies. Finally, major policy decisions have been taken by the present government in its Sixth Five-Year Plan. We have a special development plan for Baluchistan in which agricultural development plays a very important role. I would have liked to see some discussion on that aspect and how the issues which have been raised in discussions throughout are related to the specific policies which the government has adopted vis-a-vis the Baluchistan agricultre development plan. There is very little discussion of that either. And then, finally, Prof. Khan does refer to, and has referred not just once but three or four times to, the fact that there are regional inequalities regarding access to inputs and the pattern of agricultural development and growth, and yet he says very little about what a policy measure ought to be to change the existing trends or to remove original disparities. One would have liked to have seen some more discussion of this issue as well.

Assistant Professor,

Department of Economics,

Quaid-1-Azam University,

Islamabad
Ijaz Nabi 